\title{
Ecos do romantismo no cotidiano escolar: um olhar da filosofia na educação básica
}

Arlindo Alberton ${ }^{8}$ Carmen Fornari Diez ${ }^{9}$

Resumo: Este relato se refere ao trabalho pedagógico que foi desenvolvido com as turmas de terceiro ano, do período matutino, na disciplina de filosofia, da Escola de Educação Básica Casimiro de Abreu durante o mês de setembro de 2011. O trabalho teve como temática o estudo do período literário, artístico e filosófico do romantismo europeu, suas influencias no Brasil e as características deste movimento na música brasileira nas décadas de 1970 e 1980 . O objetivo foi conhecer e analisar os reflexos do romantismo durante a juventude dos pais dos alunos envolvidos no estudo. A metodologia utilizada foi investigativa, exploratória e conclusiva, tendo como ponto de partida os referenciais teóricos do romantismo, o contexto histórico dos períodos estudados, as experiências individuais dos pais e sua relação com este estilo. Conhecer a história pessoal instiga, desafia, seduz e proporciona o inestimável prazer de conhecer elementos de significância ao sujeito. As etapas e a constituição destes períodos dependeram da necessidade e da valoração que cada estudante despendeu à sua pesquisa. $\mathrm{O}$ estudo surgiu da necessidade de aproximar os conteúdos da disciplina à vida cotidiana, possibilitando um diálogo inter e entre gerações quanto aos aspectos mais significativos da percepção de concepção da existência do indivíduo na sociedade.

Palavras-chave: educação; filosofia; romantismo; música; juventude.

\section{Echos of romanticism in everyday school: a look of philosophy in basic education}

Abstract: This report refers to pedagogical work that was developed with third year morning classes, in Philosophy discipline, in Casimiro de Abreu School of Basic Education during September, 2011. The thematic work was the study of literacy, artistic and philosophical period of European romanticism, their influences in Brazil and the characteristics of this movement in Brazilian music in the 1970s and 1980s. The goal was to identify and analyze the impacts of romanticism during youth of the students parents involved in the study. The methodology used was investigative, exploratory and conclusive, taking as its starting point the theoretical frameworks of romanticism, the historical context of the studied period, the individual experiences of parents and their relationship with this style.

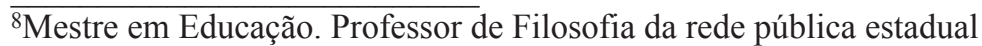
de Santa Catarina.E-mail: movephilos@gmail.com .

${ }^{9}$ Doutora em Educação (UNIMEP). Professora do Programa de Pós-Graduação - UNIPLAC. E-mail: miuxe@uol.com.br.
} 
Knowing personal history instigates, challenges, seduces and provides the priceless pleasure of identify elements of significance to the subject. The steps and the constitution of these periods depended on the necessity and valuing each student spent his own search. The study arose from the need to bring the course content to everyday life, enabling a dialogue within and among generations relating to the most significant aspects of the perception of the individual existence concept in society.

Key words: education; philosophy; romanticism; music; youth.

Tradução: William S. WEBER e Cleci C. MALUCELLI.

Submetido em: fevereiro de 2013.

Aprovado em: março de 2013.

\section{Introdução}

A busca pela compreensão dos elementos que fazem a história de um povo tende ser o propulsor na busca pelo conhecimento que faz sentido ao sujeito. $\mathrm{O}$ ensino da filosofia se propõe buscar este entendimento acerca da existência humana, seus condicionantes espaçotemporais, aspectos culturais, políticos, religiosos, artísticos... Sentir-se sujeito histórico extrapola o imediatismo histórico e fundamenta-se na compreensão da essência do próprio ser. De certa forma, todas as questões que esclarecem nossa existência, nos parecem sedutoras, seja em forma de literatura, cinema ou qualquer outra forma de expressão. Conscientes de que não é apenas a razão que move as ações humanas, mas seus sentimentos e paixões, emergiu a motivação para resgatar as características do romantismo que acompanharam o desenrolar da história da humanidade.

Ao trabalhar os conceitos do romantismo clássico do final do século XVIII e início do século XIX, com alunos de das turmas de terceiro ano do ensino médio, um grande desafio se nos apresentou: Como aproximar elementos peculiares de determinado período filosófico/literário da realidade de um jovem com idade entre 16 e 18 anos? Como não tornar as aulas uma repetição de conteúdos filosóficos que não fazem sentido para os jovens? Tais indagações soaram como um desafio à prática pedagógica e ao conformismo didático vigente, visto que somente a definição do conceito "romântico" acabaria por tornar-se tão enfadonho que desestimularia a discussão epistemológica a respeito do tema e sua relação com movimentos anteriores que determinaram seu surgimento, como o iluminismo.

O objetivo, ao trabalhar este movimento literário, era relacioná-lo com movimentos de outros períodos em suas aproximações e divergências. Partindo das características gerais do 
romantismo europeu, que depois desembarcaram na América, como valorização das emoções, liberdade de criação, amor platônico, temas religiosos, individualismo, nacionalismo e história. Num primeiro momento, buscamos comparações com elementos do cotidiano. Ao retomarmos as ideias iluministas e a revolução francesa, com seu culto à razão, percebemos influências determinantes de uma geração sobre outra. A partir de então, realizamos uma "verdadeira cruzada" rumo à geração imediatamente anterior à destes jovens que hora se encontravam diante de um dilema: Teriam seus pais vivido com tanta intensidade a juventude, em seu tempo, quanto seus filhos hoje? O que movia os jovens daquele tempo? Percebemos nossa sociedade como individualista, sedenta de emoções e extremamente criativa, mas como chegamos até aqui?

A investigação partiu de poetas e músicos clássicos do romantismo como Francisco Goya e Bocage, Herder e Goethe, de Beethoven e Chopin. Ao ressaltar as características de cada autor, iniciamos o reconhecimento destas nas poesias e canções da atualidade. A cada poema, a cada canção, surgia nova constatação. Ao afunilarmos a pesquisa para o Brasil, passeamos por poetas como Gonçalves de Magalhães, Gonçalves Dias, Álvares de Azevedo, Casimiro de Abreu, Junqueira Freire, Fagundes Varela, Sousândrade, Tobias Barreto, Castro Alves. Neste interim, remontamos as gerações literárias e suas vertentes específicas, desde o nacionalismo até o pessimismo. Aguçada a curiosidade partimos para a busca do entendimento de nosso principal objeto de desejo: Como as gerações das décadas de 1970 e 1980 se relacionaram com seu tempo, utilizando como categoria de pesquisa a expressão musical. A consequência imediata foi a agregação de informações contextualizando a investigação.

\section{Os ecos do romantismo}

De posse das características do romantismo os alunos passaram a comparar as características deste período com o estilo de vida, a moda, a TV, o cinema, a propaganda, a música, enfim, com a cultura de seus pais no período de sua juventude. A surpresa dos alunos com as descobertas se expressa nas análises produzidas logo após a primeira fase da pesquisa. $\mathrm{O}$ aluno Vinicius relatou que a pesquisa proporcionou trabalhar os aspectos que passam despercebidos no nosso dia-a-dia, a individualização do ser. De acordo com ele, o homem não sente coragem, ou esperança de tornar melhor a sua convivência... As relações do conteúdo estudado com o período da juventude dos pais foi um dos produtos mais significativos desta etapa, onde percebemos a proximidade de gerações e a influência da geração antecessora. 
Ana Carolina salienta que pensava que as gírias, o modo de se vestir, as músicas que ouvia eram criadas especialmente para sua geração, únicas e originais, porém, percebeu que para conhecer a realidade precisa buscar "razões" nos antepassados e que, não significam muitas gerações para trás, e sim, familiares com quem ainda se convive. De acordo com Andrey é interessante ver a estreita relação da história e dos pensamentos de ontem e de hoje.

Outro fator relevante foi a troca de experiências e de saberes entre os alunos. A aluna Ana Greyce salientou que adquiriu bastante conhecimento pois pode socializar com outras pessoas os temas que envolvem o romantismo e aprender muito sobre música, poesia... Já Andressa ressaltou que a pesquisa proporcionou, "primeiro de tudo", muito prazer, por que muitos jovens criticam músicas antigas por puro preconceito. Ainda, ponderou que muitas músicas são eternas e na turma a maioria curte bandas como: Legião Urbana, Engenheiros do Hawaii, Kid Abelha, Biquíni Cavadão...

A socialização do conhecimento possibilita grande satisfação ao sujeito, pois é desta forma que se sente num processo onde deve posicionar-se diante de algo, não apenas com análises de moralismo e sim, como compreensão de períodos distintos, com características comuns que repercutem até os dias atuais. Para o aluno João Paulo, aí nos damos conta que o que uma pessoa sente em um lado do mundo, pode ser o mesmo que outra sente em outro lado, por exemplo, Roxette e RPM. Tal definição, aparentemente simplória, possibilita uma ampliação na visão de mundo e de ser humano de um determinado sujeito, o que torna o trabalho extremamente significativo. Na avaliação do aluno Douglas o trabalho foi bastante difícil, pois teve que pesquisar sobre o romantismo e seus variados aspectos, além disso, buscar fontes e fatos que marcaram a época. No entanto, percebeu que realmente não sabia nada sobre a juventude de seus pais. Por outro lado, a aluna Paula salientou que o trabalho foi bastante dinâmico, os alunos dedicaram-se bastante, as fontes de pesquisa eram de fácil acesso, pois eram pessoas próximas dos pesquisadores.

A subjetividade, característica do romantismo clássico, também se fez presente nas análises dos alunos pesquisadores. De acordo com a aluna Vanessa “...as músicas antigas eram bem melhores. Eu prefiro as antigas, algumas até são tocantes, as letras são bem legais". O aluno José Mauricio questiona a respeito da revolução dos costumes, que, segundo ele, poderiam ser apenas ressaltos da relatividade dos relacionamentos. Na opinião da aluna Tainá, as músicas marcantes, roupas extravagantes e muito sentimentalismo fizeram da juventude de seus pais uma época memorável e interessante. As impressões diversas a respeito do mesmo tema demonstram a diversidade individual e o momento presente de cada 
sujeito. Ao passo que no trabalho de pesquisa desenvolveu-se, uma tendência à valorização da história pessoal dos pais, interligada com a própria história. Este aspecto tornou-se marcante no transcorrer dos trabalhos.

O individualismo, marca do romantismo, também foi percebido nas décadas dos pais destes pesquisadores. A aluna Katlen diz que o individualismo é esta manifestação individual definida por emoções e sentimentos e as músicas que seus pais gostavam expressavam exatamente isto. Jacqueline afirma que pôde ver como os pais se comportavam na época em que viviam, embora já gostasse dos artistas que foram apresentados, passou a "curtir" ainda mais. Já para Fernando, o romantismo e a relação com a época de seus pais vislumbra-se na expressão de suas emoções, que eram muitas vezes agressivas. Para Agatha as músicas românticas são identificáveis até hoje por causa de suas letras poéticas, que mexiam com as pessoas quando as ouviam. Este individualismo, uma das marcas do romantismo, foi destaque também nas décadas de 1970, 1980 e 1990 no Brasil, considerando que o País passava por momentos significativos de transformação social. Durante a década de 1970, no Brasil buscava-se o respeito às individualidades, com base na liberdade de expressão, enquanto na década de 1980, a questão estava ligada à legitimação destas liberdades e a conquista do respeito ao sujeito. Por fim, na década de 1990, com o ajuste econômico, a busca pelas realizações dos sonhos de consumo, define o individualismo.

\section{Ecos da filosofia}

A caracterização dos períodos estudados e a relação dos adolescentes com a história de seus pais ficou evidente ao final dos trabalhos. Quando o conteúdo faz sentido, há motivação na pesquisa e, talvez, esta tenha sido a grande tônica durante todo o processo realizado. Para a aluna Andressa "foi um trabalho bem legal, muita coisa aprendi pesquisando, perguntando aos mais velhos e descobrindo suas histórias". Ao ser questionada sobre o aprendizado do trabalho Ana Paula respondeu: "Estou gostando muito destes trabalhos, pois assim, posso conhecer como era a juventude da época e perceber que eles se divertiam e se contentavam com bem menos, em comparação com os jovens de agora". Ressaltando a importância da filosofia como base para a compreensão da questões que envolvem a existência humana, considera-se a pesquisa como elemento que agrega na construção do conhecimento pessoal. De acordo com os PCNs:

Considerando o critério da realidade do aluno, acredita-se que, num país de baixa literatação, como é o nosso caso, uma disciplina com o grau de abstração e contextualização conceptual e histórica, como ocorre com a filosofia, supõe que à opção de curso que for feita deve corresponder um 
cuidado redobrado com respeito às metodologias e materiais didáticos, levando sempre em conta as competências de que os alunos já dispõem e o que é necessário para introduzi-los significativamente no filosofar. (1999, p.336)

Nesta perspectiva, a tarefa de filosofar, respeita a individualidade, mas considera a sistematização como condição para a construção de um conhecimento organizado. Na fala de Ana Carolina "como exemplos de cidadãos ativos em nossa sociedade, os movimentos de lutas sociais são exemplos do fervor que ocorreu na terceira geração romântica e na época da juventude de meus pais". Sendo condição para a existência o reconhecimento da necessidade do outro, o indivíduo só percebe e desenvolve sua individualidade em relação.

Durante a exposição da proposta de trabalho, muitas surpresas ocorreram. Uma das mais marcantes se deu pela contribuição de um grupo de alunos que sugeriu fazer a pesquisa em grupo, pois todos gostavam das mesmas músicas dos pais e com isso poderiam enriquecer seus trabalhos com as contribuições dos colegas. Este fato encorajou vários outros na busca por parcerias na produção de suas pesquisas e posteriormente na elaboração de suas explanações. Ainda, durante as discussões, uma dupla apresentou-se com uma proposta que visava comparar os escritos dos autores romancistas e as cartas trocadas por seus pais durante a época do namoro. Perceberam que várias características se mantiveram como, por exemplo, a exaltação da beleza feminina, a religiosidade, o escapismo, entre outras. Exaltaram como característica que impressionou nas pesquisas a "sede pela liberdade de expressão", principalmente por expressar sentimentos que marcaram a geração de seus pais.

O contraste entre gerações, antes imaginado, se dissipou na velocidade em que ocorriam as pesquisas e a socialização dos temas descobertos. As descobertas proporcionaram maior proximidade como os colegas de sala e com a realidade dos pais. A aluna Mariana afirma que o romantismo está presente ainda hoje, claro que não nos mesmos moldes da década 1979 e 1980, não se ouve mais falar de tantos poetas românticos. Por outro lado, às músicas com características do romantismo são muito comuns e chamam a atenção aquelas que exaltam o amor, que não deve ser esquecido, pois, segundo ela, é através dele que se constrói um futuro melhor. Muitos alunos observaram a continuidade e a permanência histórica no desenvolvimento social. Para o aluno Andrey é interessante perceber a estreita relação da história e dos pensamentos do ontem e do hoje. Só muda o contexto e algumas expressões, roupas talvez, estilos musicais, cabelos... o romantismo até hoje é manifestação, expressão humana, é a condição da vida que está presente nos mais variados estilos. Retomamos assim, o intuito filosófico de sua origem: saber a descrição da vida, tudo o que se 
refere ao homem, na sua totalidade.

A tarefa do filosofar não supõe um pensamento fechado e estanque, muito menos conta com amarras que impossibilitem a formulação de ideias de acordo com o olhar daquele que investiga. Para a aluna Márcia na época do romantismo a mulher era valorizada como ser puro e perfeito, sendo hoje a "des-valorização" feminina como pureza e perfeição perceptível claramente nas músicas. O sentimentalismo, que apesar de raro, ainda está presente, principalmente no amor impossível que aparece nas músicas. Opinião compartilhada por Kimberly ao frisar que percebeu, ao longo da pesquisa, a diferença e a valorização idealizada e o desejo pela mulher. Jacqueline reconhece na música da banda RPM, "Olhar 43", características de idolatria e divinização da mulher, citando o trecho "é perigoso o seu sorriso, é um sorriso assim jocoso, impreciso, diria misterioso, indecifrável, riso de mulher". Nestas relações vislumbramos diversas percepções sobre um mesmo tema: a mulher.

Problematizar e interpretar a realidade permite ao indivíduo tomar consciência das implicações que o cercam. De acordo com Iglésias: "Sendo a maioria das pessoas pouco exigente, as explicações dadas pelo mito, ou quaisquer outras explicações prontas de uma cultura, bastam para quebrar o espanto nascente, e, assim sendo, a filosofia não acontece. [...] As pessoas crescem aceitando sem discutir os papeis sociais que lhes são atribuídos, sem jamais questionar seu valor e seu porquê, como se tudo fosse parte da ordem natural e inevitável das coisas". (IGLÉSIAS, 2005, p. 15)

Ao comparar momentos históricos distintos, buscando relações de semelhança exige do indivíduo a organização e o rigor do pensamento lógico, ferramenta esta essencial na atividade de filosofar.

\section{Conclusão}

Quando optamos por um caminho metodológico rejeitamos vários outros e assumimos os riscos, os desafios de correção, de avaliação... o processo de ensino-aprendizagem requer uma grande dose de cumplicidade dos agentes envolvidos e uma dose de determinação na direção do(s) objeto(s) de conhecimento(s). Quando indaga, espanta-se ou admira-se de alguma coisa, inicia-se o processo de ensino aprendizagem acima citado. Aí se encontra a essência da filosofia no tocante ao seu designo primordial: a admiração, o espanto, o questionamento do mundo. Tratar a filosofia nesta óptica com jovens torna-se uma atividade edificante e desafiadora ao mesmo tempo. De acordo com NAVIA (2008, p.84) "Sem dúvida, conseguir compreender e atuar sobre todos estes aspectos no contexto das complexas realidades dos 
sistemas educativos e das realidades presentes não é uma tarefa nada fácil”.

Partindo do romantismo - que muitas vezes não é tratado como movimento filosófico - buscamos valorizar conceitos relegados ao segundo plano na escala de valores intelectuais, porem, conscientes que a erudição não é tarefa da filosofia no ensino médio, nos apropriamos da dialética. O diálogo entre as correntes de pensamento, os períodos histórico e o debate acerca do tema do romantismo empolgou e estimulou na busca por respostas que melhor satisfizessem os interesses de cada um. Esta dialética de construção da proposta de trabalho foi considerada nas avaliações, como um momento de enorme satisfação e crescimento pessoal e coletivo.

A utilização da música como pano de fundo para a contextualização dos períodos estudados tornou-se disparador e motivador na agregação de novas informações, relações, ênfases, análises e consequentemente conhecimentos. Sabemos que a reflexão não pode ser ensinada formalmente, como uma técnica qualquer de uma área específica. No entanto, concordamos com KOHAN (2011) quando afirma:

A filosofia não é um saber ou um pensar, mas uma relação de afeto com o que pensamos e com o que sabemos. Ao mesmo tempo, a pergunta „como ensinar

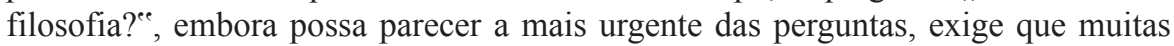
outras sejam colocadas antes, como, por exemplo, ,para que ensinar filosofia? $?^{e}$. Os sentidos da filosofia na escola podem ser múltiplos e afirmamos uma possibilidade que diz respeito à transformação do que se pensa e do que se sabe para poder tornar-se „o que se éee. (KOHAN, 2011, p.48)

Com a finalização deste trabalho percebemos, nas avaliações desenvolvidas pelos alunos - sejam elas formais e registradas, sejam orais, produzidas em debates ou em conclusões de exposições de atividades - que o ensino da filosofia pode contribuir para que o sujeito possa reconhecer-se como cidadão, como sujeito constituído de uma sociedade e que nela pode interferir e inferir, baseado em valores culturais, mas, questionando os valores estabelecidos pela sociedade vigente e buscando maior autonomia na forma de compreender o mundo.

\section{REFERÊNCIAS}

BRASIL, Ministério da Educação, Secretaria de Educação Média e Tecnológica.

Parâmetros curriculares nacionais: ensino médio. Brasília: Ministério da Educação, 1999.

IGLÉSIAS, Maura. Pré-Socráticos: Físicos e Sofistas. In: REZENDE, Antonio (Org).

Curso de filosofia: para professores e alunos dos cursos de segundo grau e de graduação. 13 ed. Rio de Janeiro: Jorge Zahar Ed., 2005. Cap 1, p. 19-50. 
KOHAN, Walter O. Sobre a obrigatoriedade do ensino de filosofia. Revista Filosofia Ciência \& Vida. São Paulo, editora escala, Ano IV, Edição 55, p.39-48, janeiro 2011. NAVIA, Ricardo. Ensino médio de filosofia nas presentes condições culturais e sociais de nossos países. In: KOHAN, Walter O. (org). Filosofia: caminhos para seu ensino. Rio de Janeiro: Lamparina, 2008. Cap 1, p. 69-84. 